\title{
Context effects in visual word recognition: Lexical relatedness and syntactic context
}

\author{
H. SCHRIEFERS \\ Nijmegen University, Nijmegen, The Netherlands \\ A. D. FRIEDERICI \\ Max-Planck-Institute of Cognitive Neuroscience, Leipzig, Germany \\ and \\ U. ROSE \\ Freie Universität Berlin, Berlin, Germany
}

\begin{abstract}
In three experiments, we investigated how associative word-word priming effects in German depend on different types of syntactic context in which the related words are embedded. The associative relation always concerned a verb as prime and a noun as target. Prime word and target word were embedded in visually presented strings of words that formed either a correct sentence, a scrambled list of words, or a sentence in which the target noun and the preceding definite article disagreed in syntactic gender. In contrast to previous studies (O'Seaghdha, 1989; Simpson, Peterson, Casteel, \& Burgess, 1989), associative priming effects were not only obtained in correct sentences but also in scrambled word lists. Associative priming, however, was not obtained when the definite article and the target noun disagreed in syntactic gender. The latter finding suggests that a rather local violation of syntactic coherence reduces or eliminates word-word priming effects. The results are discussed in the context of related work on the effect of gender dis-/agreement between a syntactic context and a target noun.
\end{abstract}

Context effects on visual word recognition have been a topic of much of the research on language processing. In a first approximation, one can distinguish between semantic and syntactic context effects. With respect to semantic context effects, word level (word-word), sentence level, and discourse level context effects can be distinguished. In the following, we will first focus on semantic context effects at the word level and at the sentence and discourse levels. Then, we will discuss the evidence on syntactic context effects. This will provide the background for the three experiments of the present study, which investigate whether and how syntactic context can influence semantic context effects.

The first type of semantic context effect, the wordword priming, or lexical relatedness, effect, refers to the finding that a word is recognized more easily when it is preceded by a semantically or associatively related word than when it is preceded by an unrelated word (see, e.g., Neely, 1990, for a review). The second type of semantic context effect concerns the effect of a sentential (or discourse level) context on the recognition of a target word. So, for example, Fischler and Bloom (1979) showed that

The present research was supported by the Alfried Krupp von Bohlen und Halbach Stiftung. We thank Liz Bates, Greg Simpson, Mike Masson, and two anonymous reviewers for comments on earlier versions of this paper. Correspondence should be sent to $\mathrm{H}$. Schriefers, Nijmegen University, NICI, P.O. Box 9104, NL-6500 HE Nijmegen, The Netherlands (e-mail: schriefers@nici.kun.nl). a target word forming a highly likely completion of a sentence frame (as determined by a cloze procedure-e.g., the word shoes for a sentence frame like "she cleaned the dirt from her ...") was recognized faster than a word forming a correct but less likely completion (e.g., hands). Finally, a word forming a semantically incorrect completion of the sentence frame (e.g., terms) produced the longest latencies.

Word-word priming can be handled easily by autonomous theories of word recognition. According to such theories, the only source of facilitation in word recognition are processes occurring within the mental lexicon. Priming is assumed to be due to a fast-acting and automatic spreading of activation between semantically related words in the lexicon (see, e.g., Seidenberg, Tanenhaus, Leiman, \& Bienkowski, 1982; Stanovich \& West, 1983). The sentence frame priming is more difficult to handle for such autonomous theories of word recognition. In the examples given above, there is no associative relation between any of the words in the sentence and the target word. Therefore, the facilitation effect (shoes vs. hands) cannot be due to lexical-lexical priming. One possible account for these facilitation effects within an autonomous model of word recognition assigns these effects to a positive response bias following the occurrence of a predictable target word. That is, the facilitation effect is ascribed to a postlexical decision stage. Similarly, the inhibition observed with incorrect sentence completions is assigned to a perceived mismatch between sentence frame and tar- 
get. This mismatch is also assumed to influence the postaccess decision stage. Some evidence in favor of this interpretation comes from studies showing that at least some context effects obtained with the (binary) lexical decision task are reduced or eliminated in naming tasks that should not include a postaccess decision stage (see, e.g., Lorch, Balota, \& Stamm, 1986; Seidenberg, Waters, Sanders, \& Langer, 1984; West \& Stanovich, 1982).

Other theoretical proposals assume that, in a first stage of lexical processing, a list of potential targets (or candidate words) is activated on the basis of an initial analysis of the target stimulus. In a second stage, the eventual selection of one candidate from this list of candidate words takes place. This latter stage can be influenced by contextual information other than lexical-lexical priming (see, e.g., Rueckle \& Oden, 1986; Sanocki et al., 1985; Zwitserlood, 1989).

A different view of context effects on lexical processing in language comprehension is given by discourseoriented models (see Hess, Foss, \& Carroll, 1995, for an overview). According to discourse-oriented models, lexical processing is directly affected by the ongoing representation above the word level. Two subclasses of discourse models can be distinguished (see Hess et al., 1995). According to the first subclass (see, e.g., Foss \& Ross, 1983; Foss \& Speer, 1991), "context effects are the result of facilitated integration of some target word into the ongoing discourse representation" (Hess et al., 1995, p. 63)that is, context effects arise outside the lexicon. According to the second subclass, context effects are due to topdown activation from the discourse representation, directly affecting the activation of lexical entries in the mental lexicon (see, e.g., Auble \& Franks, 1983). Finally, some models of context effects can be dubbed hybrid models (see Hess et al., 1995). According to these models, local and global sources contribute to the context effects (see, e.g., Schustack, Ehrlich, \& Rayner, 1987).

So far, we have mentioned studies of lexical-lexical priming between associatively related words, on the one hand, and studies of sentence context effects that occur in the absence of associative or lexical relatedness between a word in the sentence frame and the target word, on the other hand. Recently, however, O'Seaghdha (1989) and Simpson, Peterson, Casteel, and Burgess (1989) have approached the question of lexical-lexical priming effects and sentence context effects from a different perspective (see also Masson, 1986). These authors contrast the priming between a prime word and an associatively related target word occurring either in a grammatical sequence of words or in a scrambled (ungrammatical) list of words. The logic behind these studies is roughly as follows. If priming effects occur in grammatical sequences but not in scrambled word lists, lexical relatedness between a prime word and a target word alone is not sufficient to explain sentence context effects on word recognition, even in a situation in which the sentence contains two associatively related words. This logic is, in a sense, the opposite of the logic behind the sentence-priming studies mentioned above, which address the question of whether sentence context effects can be obtained in the absence of lexical relatedness. The just-mentioned studies, by contrast, ask whether semantic and syntactic correctness of a sentence is a necessary condition for obtaining priming effects between two associatively related words in a sentence.

In the experiments to be reported below, we extend the studies of O'Seaghdha (1989) and Simpson et al. (1989). Like the experiments of $O$ 'Seaghdha and Simpson et al., our experiments use a scrambling manipulation. However, the main focus will be on a different manipulation of syntactic context: the match or mismatch of grammatical gender between a definite article in the prime and a target noun. Do word-word priming effects obtain irrespective of a gender match or mismatch, or does a gender mismatch reduce word-word priming effects? Before turning to this question, we will briefly discuss the studies of O'Seaghdha and Simpson et al.

O'Seaghdha (1989) presented his subjects with short phrases containing either two lexically related nouns (e.g., "the author of this Book") or two lexically unrelated nouns (e.g., "the author of this FLOOR"). The contexts were presented word by word, with different presentation rates ranging from 200 to $800 \mathrm{msec}$ per word in different experiments. The target word was presented in uppercase letters, and the subjects had to make a lexical decision on this target. In all experiments, this condition (referred to as the syntactic condition by O'Seaghdha) showed shorter lexical decision times for target nouns that were related to the noun in the prime than for unrelated target nouns. Following O'Seaghdha and Simpson et al. (1989), we refer to the respective conditions as related and unrelated. It should be noted, however, that this choice of labels is not really adequate, as the targets in the unrelated condition were semantically inappropriate completions of the prime fragment (e.g., "the author of this FLOOR").

In a second condition, called the scrambled condition, the words in the prime fragment were scrambled so that they did not result in a syntactically well-formed sequence (e.g., "the author the and BOOK/FLOOR"). The lexical decision times for the scrambled-related and scrambledunrelated conditions did not differ significantly.

Although these results suggest that a priming effect only occurs in grammatical sequences, they are not easy to interpret, since the syntactic-unrelated condition contains targets that are semantically inappropriate continuations of the prime fragment (see above). Therefore, it is difficult to determine whether the difference between the related and unrelated conditions with grammatical phrases is due to inhibition in the unrelated condition, facilitation in the related condition, or a combination of both effects. This question was addressed in an additional experiment (O'Seaghdha, 1989, Experiment 5) in which latencies to appropriate but unlikely completions as targets (e.g., "the owner of the Book") was taken as a neutral baseline against which facilitation of probable and associatively 
related completions (e.g., "the author of the Book") was measured. This experiment contained exclusively grammatical sequences. The results show a facilitation effect, as measured against this neutral baseline, as well as an inhibition effect for corresponding items with inappropriate completions (e.g., "the author of the FLOOR"). However, as this last experiment does not contain the scrambled condition, this study does not provide us with a direct within-experiment comparison of facilitation effects (as measured against a baseline with an appropriate but unlikely completion) for the grammatical and the ungrammatical scrambled conditions.

Simpson et al.'s (1989) study is closely related to the study by O'Seaghdha (1989). However, in contrast to O'Seaghdha, the subjects had to perform a naming task on the critical targets, and a neutral baseline condition was included (e.g., "They did not know that the next word might be TABLE"; see, e.g., Stanovich \& West, 1979). Simpson et al.'s study yielded the same pattern of results as $O$ 'Seaghdha's study: a facilitation effect in syntactically correct sentences, but only small and insignificant facilitation effects in scrambled word lists.

The present experiments extend the just-mentioned studies by using not only scrambled word lists but also a more local violation of syntactic coherence than the scrambling of words. In particular, we contrast priming effects in grammatically correct prime-target sequences (e.g., related: "Er trinkt den WEIN"-He drinks the [masc.] WINE [masc.]; unrelated: "Er sieht den WEIN"He sees the [masc.] WINE [masc.]) with the priming effects in corresponding sentences containing a gender mismatch between the prime and the target (e.g., related: "Er trinkt das WEIN"--He drinks the [neuter] WINE [masc.]; unrelated: "Er sieht das WEIN"-He sees the [masc.] WINE [masc.]).

As this manipulation of the syntactic congruency between a sentence fragment and a target word will be central in the experiments reported below, we will briefly discuss the effects of syntactic context on lexical processing, focusing primarily on studies concerning gender congruency. Most syntactic priming studies have investigated the effect of a context (e.g., a sentence beginning) on the lexical processing of a target word that syntactically is either congruent or incongruent with the context. With respect to the syntactic incongruency used in different studies, two main classes can be distinguished (see Colé \& Segui, 1994). On the one hand, most studies conducted in English have used syntactic category violations in the syntactically incongruent conditions; the target word belonged to a syntactic category that, given the grammatical rules of the language, was not allowed to occur after the prime (see, e.g., Seidenberg et al., 1984; West \& Stanovich, 1986; Wright \& Garrett, 1984). Other studies manipulated syntactic incongruency on the level of morphosyntactic agreement. These studies have primarily been conducted in Serbo-Croatian and concern number, gender, and case agreement between context and target (see, e.g., Gurjanov, Lukatela, Moskoljevic, Savic, \& Turvey,1985; Katz, Boyce, Goldstein, \& Lukatela,
1987; Lukatela, Carello, \& Turvey, 1990; Lukatela, Kostic, Todorovic, Carello, \& Turvey, 1987). For Hebrew, Deutsch and Bentin (1994) investigated gender and number agreement between the subject and the verb and a morphosyntactic rule that involves the decomposition of the conjunctive form of Hebrew pronoun-plus-preposition constructions.

The main grammatical congruency manipulation in the present experiments concerns gender agreement between article and noun. The effect of gender marking on a prime for the recognition of a target noun has been investigated for French by Colé and Segui (1994) and by Grosjean, Dommergues, Cornu, Guillelmon, and Besson (1994). Colé and Segui visually presented their subjects with a gender-marked open class or closed class word (an adjective or a possessive pronoun, respectively) as prime, followed by a noun as the target. The prime and the target agreed with respect to gender and number, or they disagreed with respect to either gender or number. Lexical decision times for syntactically incongruent prime-target pairs were longer than those for syntactically congruent prime-target pairs.

Grosjean et al. (1994) investigated the recognition of spoken nouns in French as a function of gender marking on a preceding prime. In a neutral condition, the prime was an auditorily presented adjective that was not marked for syntactic gender. In the other condition, the prime adjective was marked for syntactic gender. In this condition, the adjective and the target noun always agreed with respect to syntactic gender. In a gating experiment, the target nouns were recognized at earlier gates in the condition with congruent gender marking than in the neutral condition without gender marking. In an auditory lexical decision experiment, the authors obtained comparable effects; lexical decision times for the target nouns were longer in the gender-neutral priming condition than in the condition with a congruent gender marking.

Related evidence for Italian has recently been obtained by Bates, Devescovi, Hernandez, and Pizzamiglio (1996; see also Bates, Devescovi, Pizzamiglio, d'Amico, \& Hernandez, 1995). In this study, the subjects heard pairs of words consisting of an adjective and a noun; the subjects were instructed to repeat the second word of each pair. The adjective and the noun either disagreed in grammatical gender (e.g., BRUTTO TORRE--ugly [masc.] tower $[\mathrm{fem}$.$] ) or agreed in grammatical gender (e.g.,$ BRUTTA TORRE-ugly [fem.] tower [fem.]). A third condition with gender-ambiguous adjectives served as a neutral baseline (e.g., GRANDE TORRE - great [amb.] tower [fem.]). The word repetition times showed both significant facilitation in the gender agreement condition and significant inhibition in the gender disagreement condition, relative to the neutral baseline. Bates et al. (1995, p. 860) interpret this as evidence "which suggests that gender priming may involve a combination of prelexical as well as postlexical effects." An obvious interpretation of the prelexical effects would be in terms of the gendermarked prime activating all lexical entries of matching gender. However, it has also been argued that priming of 
lexical items from syntactic information (here, e.g., gender) is probably rather inefficient because the set of lexical items primed by syntactic information would be very large and, therefore, priming will fail to discriminate among possible alternatives (for a discussion of this aspect, see Tanenhaus, Dell, \& Carlson, 1987).

Let us now turn to the experimental conditions used in our experiments. Eight different conditions were used in the first experiment (see Table 1).

In the first two conditions ( $A$ and $B$ ), the subjects were presented with sentence fragments consisting of a personal pronoun, a transitive verb, and a definite article. The target was always a noun. The sentence fragment and the target noun together formed a grammatical and semantically correct German sentence. In A, the verb write and the noun letter are close associates, whereas, in B, the verb see and the noun letter are associatively unrelated, but letter is an appropriate completion of the sentence. The subjects were instructed to make a lexical decision on the noun target. These two conditions should establish our basic priming effect.

The next two conditions were derived from $A$ and $B$ by scrambling the words in the sentence fragment so that a syntactically incoherent sequence of words results, as in $\mathrm{C}$ and $\mathrm{D}$. These conditions parallel the scrambled condition in O'Seaghdha's (1989) and Simpson et al.'s (1989) studies. Conditions A through D provide a direct comparison of potential facilitation effects in syntactically correct and scrambled word sequences.

Of central interest in the present study are the conditions manipulating the syntactic gender match between the definite article and the target noun ( $E$ and $F$ ). In German, the definite article is marked for gender and case

\section{Table 1}

Examples of Materials Used in Experiment 1

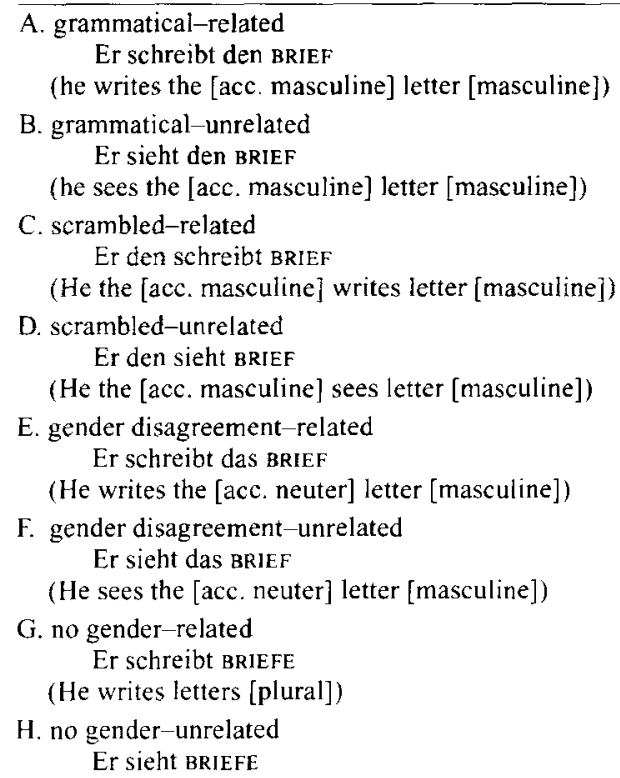

(and number). The definite article for masculine nouns in the accusative is den and for neuter nouns in the accusative das. In conditions $\mathrm{A}$ and $\mathrm{B}$, the target noun (e.g., BRIEF, a masculine noun) always matched the definite article in the sentence fragment. In conditions $C$ and $D$, the sentence fragments are scrambled, but, as there is only one definite article in the prime and only one target noun, we also refer to these conditions as containing a match between the definite article and the target noun. Conditions $\mathrm{E}$ and $\mathrm{F}$ were derived from conditions $\mathrm{A}$ and $\mathrm{B}$ by replacing the definite article den by the definite article das if the target noun had masculine gender (as did the noun BRIEF), or vice versa if the target noun had neuter gender. The resulting sequences are incorrect on a morphosyntactic level, because of a gender disagreement between the definite article and the target noun. In contrast to conditions $\mathrm{C}$ and $\mathrm{D}$, the sentence frame preceding the target is grammatical. The morphosyntactic incorrectness of the whole prime-target sequence becomes obvious on the target noun. In this condition, we expect a general prolongation of latencies, as compared with conditions $\mathrm{A}$ through $\mathrm{D}$. This inhibition should be due to the morphosyntactic mismatch between the prime fragment and the target noun. Such inhibition effects have been reported for German article-noun sequences in which the article did not match the target noun's syntactic gender (Schmidt, 1986; see also Colé \& Segui, 1994, for corresponding results in French) and for sentence frames of the type used in the present study (Friederici \& Schriefers, 1994)

In addition to this general prolongation of lexical decision times in this condition, there is the question of whether a facilitation effect in the related, as compared with the unrelated, condition will be obtained. Let us consider this question first from the perspective of discourse-oriented models of context effects. For models assuming that context effects are the result of facilitated integration of the target word into the ongoing discourse (or, in our case, sentence) representation (see, e.g., Foss \& Ross, 1983), the detection of a gender disagreement between article and noun might block any attempt for integrating the target noun into the sentence representation. That is, integration into the sentence representation occurs only for words forming a grammatically coherent string.

On the other hand, there are models allowing for a direct top-down influence of the sentence representation on the activation of entries in the mental lexicon. For the present situation, there appear to be two versions of a localist view. Under the first one, a verb like writes will prime all nouns referring to writable things in the mental lexicon. But the definite article (e.g., das in $\mathrm{E}$ and $\mathrm{F}$ of Table 1) will restrict the set of candidate words to only those nouns referring to writable things that have neuter gender (e.g., Buch [book]). That is, the definite article will, so to speak, channel the lexical-lexical priming of nouns by the verb to a particular subset of these nouns. The remaining set of primed gender-matching nouns will therefore not include the actual target noun Brief, which has masculine gender. As a consequence, there should 
be no priming of the target noun Brief in E, as compared with $F$. This view does not make the assumption that syntactic information can activate large zones of the mental lexicon (i.e., all nouns of a particular syntactic gender). Rather, gender information serves as context information that reduces the set of semantically primed candidate words.

Under the second version of a localist view, the article will add additional activation to all gender-matching nouns (but see Tanenhaus et al., 1987, who argue that such an activation of large zones of the mental lexicon is probably computationally intractable). Under this view, gendermismatching nouns also should still be primed by the verb, but gender-matching nouns will receive additional priming by the definite article. Since neither in the related nor in the unrelated condition does the target belong to the set of gender-matching nouns, the priming effect should not be influenced by the gender mismatch. As a consequence, we should obtain facilitation effects in $\mathrm{E}$, as compared with $\mathrm{F}$.

The latter view could also have consequences for our conditions A and B. One could hypothesize that, in the related condition, the verb primes a set of semantically related nouns (e.g., writes primes all nouns referring to writable things) and that the gender information of the article gives an additional boost of activation to the specific subset of these nouns with the matching syntactic gender. If this were the case, the priming effect in $A$, as opposed to $B$, might be larger than the priming effect to be expected in the absence of gender information from the prime fragment. In order to be able to control for this possibility, we introduced conditions $\mathrm{G}$ and $\mathrm{H}$, in which the subjects were presented with grammatical word sequences not containing a definite article. In these conditions, the target nouns are used in their plural forms. This allows us to drop the definite article. If the presence of the correct definite article in A and B does not specifically contribute to the priming effect, the priming effect in $G$, as opposed to $H$, should be of the same size as the priming effect in $\mathrm{A}$, as opposed to $\mathrm{B}$. If, however, the definite article contributes to the size of the priming effect in $A$, as opposed to $B$, this priming effect should be larger than in condition $\mathrm{G}$, as opposed to $\mathrm{H} .{ }^{l}$

\section{EXPERIMENT 1}

In Experiment 1, three main questions were addressed. First, is the lexical relatedness effect dependent on the syntactic correctness of the prime, as suggested by O'Seaghdha (1989) and Simpson et al. (1989; conditions A and $B$ vs. $C$ and D)? Second, is the lexical relatedness effect reduced when the priming sentence fragment is grammatical but the target noun and the definite article of the sentence fragment mismatch with respect to syntactic gender (conditions A and B vs. E and F)? Third, does the presence of the correct definite article in grammatical sequences contribute to the size of the priming effect (conditions A and B vs. G and $\mathrm{H}$ )?

\section{Method}

Subjects. Sixty-four native speakers of German participated in this experiment, most of them students at the Free University of Berlin. All the subjects reported having normal or corrected-tonormal vision.

Materials. In order to address the issues discussed above, we needed word triplets consisting of two transitive verbs and a noun, such that, within each triplet, one of the verbs primes the noun relative to the other verb of the triplet. Because there are, to our knowledge, no German norms for the association strength between verbs and nouns, we decided to run a simple word-word (verbnoun) priming experiment for the selection of adequate materials for Experiment 1.

Sixty-two triplets, each consisting of 2 transitive verbs and a noun, were selected for this pilot experiment. Within each triplet, the noun was, according to the authors' intuitions, closely associated with one of the verbs but not with the other verb. This resulted in 62 verb-noun pairs with high associative relatedness and 62 verb-noun pairs with low associative relatedness. All the nouns had either masculine or neuter syntactic gender. ${ }^{2}$ Sixty-two orthographically and phonologically legal nonwords were constructed by replacing one letter in German nouns. None of the nouns used in the generation of the nonwords occurred in the list of the 62 target nouns. For each of these nonwords, a transitive verb was selected as a prime. None of these 62 verbs occurred in the list of 124 prime verbs for the critical word trials.

Two experimental lists were constructed. Both lists contained the same 62 verb-nonword pairs. For the critical verb-noun pairs, each list contained 31 trials in which the verb and the noun were associatively related and 31 trials in which they were unrelated. Each target noun occurred only once in each experimental list (either in the related or in the unrelated condition). If a target noun occurred in the related condition in one of the two experimental lists, the same target noun occurred in the unrelated condition in the other list (and vice versa).

Eight subjects were run on the first experimental list, and 8 subjects on the second experimental list. The subjects were seated at a distance of approximately $0.80 \mathrm{~m}$ from a computer screen on which primes and targets were presented and gave the lexical decision responses by means of a panel with two pushbuttons. The prime verbs were presented in lowercase in their infinitive form, the targets in uppercase, as black letters on a white background.

Each trial started with a fixation cross, which was presented in the middle of the screen for $90 \mathrm{msec}$. Directly thereafter, the prime verb was presented for $620 \mathrm{msec}$. The prime was followed immediately by the target, which stayed on the screen for $1,300 \mathrm{msec}$. Reaction times were measured from the start of the presentation of the target to the subject's pushbutton response. The fixation cross announced the beginning of the next trial $2,000 \mathrm{msec}$ after the end of the presentation of the target.

The complete set of 62 target nouns showed a reliable priming effect $[t(15)=3.07, p<.01]$. For each target noun, the mean lexical decision time in the related and in the unrelated condition was computed. These means showed a priming effect for 40 of the 62 target nouns. ${ }^{3}$ The corresponding 40 triplets, consisting of two transitive verbs and a target noun, were selected for Experiments 1-3. Twenty-three of these 40 target nouns had neuter gender; the remaining 17 had masculine gender.

For Experiment 1, four word sequences were constructed from each verb-noun combination. The grammatical sequences (conditions $\mathrm{A}$ and $\mathrm{B}$ ) consisted of the masculine third person singular pronoun er, a verb in third person singular, a definite article in its accusative form (either masculine den or neuter das, depending on the target noun's gender), and the target noun (see Table 1). The scrambled condition was derived from this condition by interchanging the verb and the article, yielding sequences like $C$ and $D$. The conditions $\mathrm{E}$ and $\mathrm{F}$, which will be referred to as gender dis- 
agreement hereafter, were derived from $\mathrm{A}$ and $\mathrm{B}$ by replacing the accusative neuter definite article (das) by the accusative masculine article (den) in the case of a neuter target noun, or vice versa in the case of a masculine target noun. Finally, the grammatical sentences without a definite determiner (see $G$ and $H$ ) were derived from the grammatical sentences by dropping the definite article and putting the target noun in its plural form. This condition will hereafter be referred to as the no-gender condition.

Experiment 1 had eight experimental conditions, which resulted from the combination of the factors associative relatedness (the prime verb and target noun were associatively related or unrelated) and syntactic context (grammatical, scrambled, gender disagreement, no-gender). Eight experimental lists were constructed such that, within each list, 5 of the 40 target nouns occurred in one of the eight conditions and each target noun occurred only once. Across the eight experimental lists, each target noun occurred precisely once in each of the eight conditions. ${ }^{4}$

From the 40 verb-nonword pairs, 40 trials were constructed. The prime parts of these trials (i.e., the part preceding the nonword) were equally distributed across the four levels of the syntactic context condition. As a result, the subjects could not use the occurrence of a specific syntactic context for predicting whether a word or a nonword target was going to follow. In addition, 20 practice items were constructed (10 with words as targets and 10 with nonwords as targets). Each experimental list consisted of 100 trials ( 20 practice trials, 40 nonword trials, and 40 word trials). Two randomizations of the experimental lists were constructed.

Procedure. Sixty-four subjects participated in the experiment. Eight subjects were run on each of the eight experimental lists, 4 in each of the two randomizations. Each experimental trial started with the presentation of a fixation cross in the middle of the screen for $90 \mathrm{msec}$. Immediately after offset of the fixation cross, the prime (e.g., "Er schreibt den") was presented. After $800 \mathrm{msec}$ the prime was replaced by the target, which was presented in uppercase letters. The target remained on the screen for $1,300 \mathrm{msec}$. Lexical decision latencies were measured from the appearance of the target to the subject's pushbutton response. The fixation cross was presented, announcing the start of the next trial, 2,000 msec after the target had disappeared from the screen.

\section{Results and Discussion}

Trials with incorrect lexical decisions or with reaction times longer than a timeout of $2,000 \mathrm{msec}(2 \%$ of all data points) were excluded from further analysis. All reaction times deviating more than two standard deviations from a subject's and an item's mean ( $2.9 \%$ of all data points) were replaced by estimates (Winer, 1971). Table 2 gives the mean lexical decision times (in milliseconds) and the percentages of incorrect lexical decisions in the eight experimental conditions.

The results were analyzed in two analyses of variance (ANOVAs), one by subjects and one by items, with the factors relatedness (related, unrelated) and syntactic context. In the remainder of this article, effects are referred to as being significant when they are associated with a $p$-value smaller than .05 .

The factor relatedness was significant $\left[F_{1}(1,63)=\right.$ $\left.37.5, M S_{\mathrm{e}}=2,087 ; F_{2}(1,39)=32.1, M S_{\mathrm{e}}=1,524\right]$, as was the factor syntactic context $\left[F_{1}(3,189)=49.3, M S_{\mathrm{e}}=\right.$ 1,$\left.883 ; F_{2}(3,117)=19.8, M S_{\mathrm{e}}=2,935\right]$. The interaction of the two factors did not reach significance $\left[F_{1}(3,189)=\right.$ $\left.1.8, M S_{\mathrm{e}}=1,909 ; F_{2}(3,117)=1.7, M S_{\mathrm{e}}=1,325\right]$.

The results of this overall ANOVA indicate that we obtained a significant priming effect that is not modulated by the different syntactic context conditions. However, descriptively the priming effect in the gender disagreement condition $(14 \mathrm{msec})$ is approximately halved, as compared with the remaining three context conditions $(30 \mathrm{msec}$, $23 \mathrm{msec}$, and $33 \mathrm{msec}$, in the grammatical, scrambled, and no-gender conditions, respectively). The failure to obtain a significant interaction in the overall ANOVA might be due to an insufficient power of the design and to the related general problem with observing such interactions in this kind of design (see Wahlsten, 1991). However, it has been argued that multiple comparison procedures controlling for Type I error probability can be used, regardless of whether the corresponding overall $F$-value is significant (Wilcox, 1987). A Newman-Keuls test on the eight means of Table 2 shows that the related and unrelated conditions differ significantly (by subjects and by items) for the grammatical, the scrambled, and the no-gender conditions but not for the gender disagreement condition. The Newman-Keuls tests further showed that the grammatical and the scrambled conditions did not differ but had shorter latencies than the gender disagreement condition and the no-gender condition, which did not differ from each other. In the discussion section of Experiment 2, we will show that, when increasing the power of the analyses by collapsing comparable conditions of Experiments 1 and 2 into one common analysis, the syntactic context $\times$ relatedness interaction reaches significance. Furthermore, Experiment 3 will provide a direct test of the syntactic context (grammatical vs. gender disagreement) $\times$ relatedness (related vs. unrelated) interaction with increased statistical power.

Taken together, the grammatical sentences produced a reliable priming effect. A comparison with the no-gender condition suggests that this priming effect is not enhanced by the presence of a correct definite article in the prime;

Table 2

Lexical Decision Times (in Milliseconds) as a Function of Syntactic Context and Lexical Relatedness in Experiment 1 Syntactic Context

\begin{tabular}{|c|c|c|c|c|c|c|c|c|c|c|c|c|}
\hline \multirow[b]{2}{*}{ Relatedness } & \multicolumn{3}{|c|}{ Grammatical } & \multicolumn{3}{|c|}{ Scrambled } & \multicolumn{3}{|c|}{$\begin{array}{c}\text { Gender } \\
\text { Disagreement }\end{array}$} & \multicolumn{3}{|c|}{ No-Gender } \\
\hline & $\begin{array}{l}\text { Decision } \\
\text { Times }\end{array}$ & $S D$ & $\begin{array}{c}\overline{\%} \\
\text { Incorrect }\end{array}$ & $\begin{array}{l}\text { Decision } \\
\text { Times }\end{array}$ & $S D$ & $\begin{array}{c}\% \\
\text { Incorrect }\end{array}$ & $\begin{array}{l}\text { Decision } \\
\text { Times }\end{array}$ & $S D$ & $\begin{array}{c}\% \\
\text { Incorrect }\end{array}$ & $\begin{array}{l}\text { Decision } \\
\text { Times }\end{array}$ & $S D$ & $\begin{array}{c}\% \\
\text { Incorrect }\end{array}$ \\
\hline$\overline{\text { Related }}$ & 557 & 92 & 0.9 & 567 & 105 & 1.2 & 615 & 117 & 0.9 & 605 & 117 & 2.8 \\
\hline Unrelated & 587 & 113 & 1.6 & 590 & 107 & 1.2 & 629 & 124 & 3.4 & 638 & 130 & 4.7 \\
\hline$M$ & 572 & & & 579 & & & 622 & & & 622 & & \\
\hline
\end{tabular}


the priming effects in these conditions are of almost the same magnitude ( 30 and $33 \mathrm{msec}$, respectively). The overall prolongation of latencies in the no-gender condition, relative to the grammatical condition $(622 \mathrm{msec} v$ s. $572 \mathrm{msec}$ ), could be due to the fact that the targets in the no-gender condition are plural noun forms, and, thus, morphologically and orthographically more complex than the corresponding singular forms in the syntactically correct condition.

The gender disagreement condition reduces the priming effect to a nonsignificant $14 \mathrm{msec}$. According to discourseoriented models of context effects, this could be due to the blocking of integration processes by a perceived gender mismatch between the article and the noun. But it could also be accounted for by a localist lexical view of context effects (see above). Whatever the ultimate account of the results might be, they show that syntactic incoherence reduces or eliminates lexical-lexical (here verbnoun) priming effects. In this respect, the present results converge with those reported by O'Seaghdha (1989) and Simpson et al. (1989).

On the other hand, however, the scrambled condition shows a reliable priming effect. This latter result is in conflict with the results reported by O'Seaghdha (1989) and Simpson et al. (1989). It could be the case, however, that the type of sentences, the type of scrambling, or the presentation mode of the prime fragments give the subjects the possibility of reconstructing a grammatical sequence from the scrambled prime. An alternative account would attribute the priming effect in the scrambled condition to the direct adjacency of the prime verb and the noun target. This would be in line with Simpson et al.'s finding that lexical-lexical priming can be obtained with scrambled word lists, if the prime word and the related target word occur directly adjacent to one another. These issues will be taken up in Experiment 2.

\section{EXPERIMENT 2}

Experiment 2 again used four different syntactic context conditions, with associatively related, as opposed to unrelated, verb-noun pairs in each of the syntactic context conditions. The critical verbs and target nouns were the same as those in Experiment 1. Table 3 gives examples of the materials in these conditions.

The first syntactic context condition in Experiment 2 was the grammatical condition of Experiment 1 (see A and B in Table 3). As in Experiment 1, it establishes the basic priming effect.

The second syntactic context condition, the scrambled condition, was derived from the scrambled condition of Experiment 1 by reordering the words in the prime fragment in the order verb-article-pronoun. The resulting sequences (see $C$ and $D$ in Table 3 ) are again ungrammatical in the prime fragment, but now the critical verb and the associatively un-/related noun are not adjacent,
Table 3

Examples of Materials Used in Experiment 2

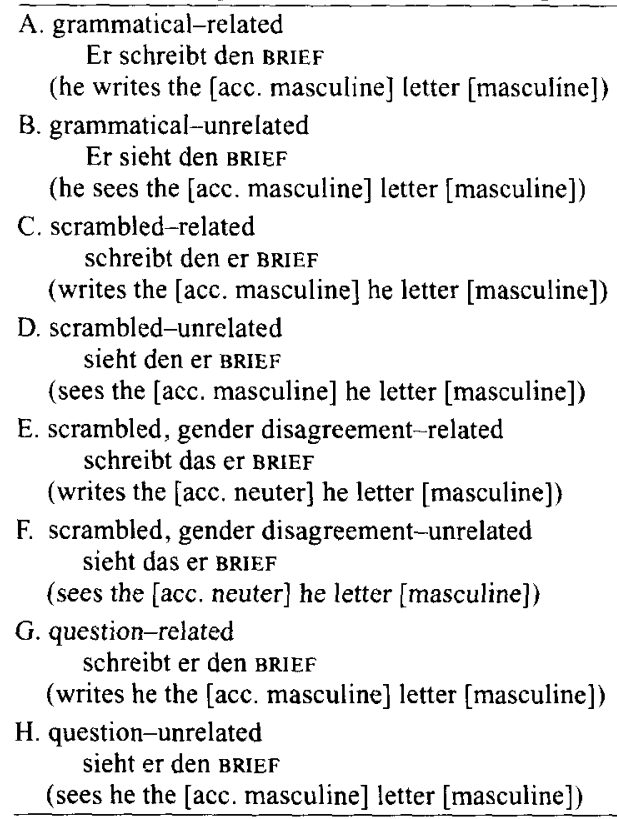

Note-Targets are given in uppercase.

but rather separated by two intervening words. These conditions should provide an answer to the question of whether the priming effects observed with the scrambled condition in Experiment 1 are due to the direct adjacency of the prime verb and the target noun.

The third syntactic context condition was derived from $C$ and $D$ by replacing the accusative neuter article with the accusative masculine article or vice versa. This condition, exemplified in Table 3 as $\mathrm{E}$ and F, will hereafter be called the scrambled gender disagreement condition. In this condition not only are the words of the prime fragment scrambled, but, in addition, the definite article of the scrambled sequence does not match the target noun's syntactic gender. This condition should provide an answer to the question of whether subjects reconstruct the scrambled sequences as grammatical sentences while reading the prime fragment. If this is the case, one would expect that the priming effect in conditions $\mathrm{E}$ and $F$ is reduced in the same way as it was the case of the gender disagreement (but unscrambled) condition in Experiment 1 (see $E$ and $F$ in Table 1).

The fourth syntactic context condition was a grammatical sequence of words in the form of a yes/no question in which the verb occurs in the sentence-initial position (see $\mathrm{G}$ and $\mathrm{H}$ ). This condition will be called the question condition hereafter. This condition allows us to assess whether the distance between the verb and the target noun, in terms of the number of intervening words, has an influence on the amount of priming in grammatical sentences. Furthermore, this condition guarantees 
that, as in Experiment 1, half of the critical trials are grammatical prime-target sequences and half of them are ungrammatical prime-target sequences.

\section{Method}

Subjects. Sixty-four native speakers of German, most of them students at the Free University of Berlin, served as subjects in this experiment. All the subjects reported having normal or correctedto-normal vision. No subject had participated in the pilot experiment or in Experiment $\mathrm{l}$.

Materials. The materials for the critical trials were derived from the materials of Experiment 1 in the way described above. In each of the eight experimental lists, the sentence fragments of the scrambled condition of Experiment 1 were replaced by the sentence fragments of the new scrambled condition. The sentence fragments of the gender disagreement condition of Experiment 1 were replaced by the sentence fragments of the new scrambled gender disagreement condition. And the sentence fragments of the no-gender condition of Experiment 1 were replaced by the sentence fragments of the new question condition. The grammatical condition remained the same as that in Experiment 1 . The sentence fragments for the nonword trials were replaced in precisely the same way. In all remaining aspects (experimental versions, randomizations), the materials were the same as those in Experiment 1.

Procedure. The procedure was the same as that in Experiment 1, with one exception. Because we wanted to keep the presentation of target nouns precisely the same as that in the preceding experiment, the target nouns in the question condition were not followed by a question mark. In order to ensure that subjects would really read these sentences as yes/no questions, we explicitly mentioned the occurrence of such sentences in the instructions.

\section{Results and Discussion}

The results were analyzed in the same way as that in Experiment 1. In $1.2 \%$ of the critical trials, the subjects had given an incorrect lexical decision response or not responded within the timeout of $2,000 \mathrm{msec}$. These data points were excluded from further analyses. An additional $3.2 \%$ of all data points was identified as extreme reaction times and replaced by estimates in the same way as that in Experiment 1. Table 4 gives the mean lexical decision times and the corresponding percentages of incorrect responses as a function of syntactic context conditions and lexical relatedness.

The overall ANOVAs revealed a reliable priming effect (related vs. unrelated) $\left[F_{1}(1,63)=10.6, M S_{\mathrm{e}}=2,358\right.$; $\left.F_{2}(1,39)=6.2, M S_{\mathrm{e}}=2,519\right]$ and a significant main effect of the factor syntactic context $\left[F_{1}(3,189)=22.98\right.$, $\left.M S_{\mathrm{e}}=1,901 ; F_{2}(3,117)=5.5, M S_{\mathrm{e}}=4,928\right]$. The interac- tion of these two factors was not significant $\left[F_{1}(3,189)=\right.$ $\left.1.7, M S_{\mathrm{e}}=1,851 ; F_{2}(3,117)=1.9, M S_{\mathrm{e}}=1,260\right]$.

Newman-Keuls tests (by subjects and by items) on the eight means of Table 4 showed that the priming effect (related vs. unrelated) is significant in the grammatical $(21 \mathrm{msec})$ and scrambled conditions $(19 \mathrm{msec})$ but not in the scrambled gender disagreement $(7 \mathrm{msec})$ and question conditions $(9 \mathrm{msec})$. The Newman-Keuls test also showed that the scrambled gender disagreement condition had longer latencies than the remaining three conditions, which did not differ from each other.

The present results show that the presence of a priming effect in the scrambled condition in Experiment 1 (see $C$ and $D$ in Table 1) is not due to the direct adjacency of verb and target noun. As in Experiment 1, the scrambled condition of Experiment 2( $\mathrm{C}$ and $\mathrm{D}$ in Table 3 ) shows the same priming effect as the grammatical condition (19 $\mathrm{msec}$ and $21 \mathrm{msec}$, respectively), despite the fact that now the verb and the target noun in the scrambled condition are separated by two intervening words.

On the other hand, the scrambled gender disagreement condition of the present experiment ( $E$ and $F$ in Table 3) behaves like the gender disagreement condition of Experiment 1 ( $E$ and $F$ in Table 1), in which the prime fragment was not scrambled. Again, the priming effect is reduced when the article of the prime fragment and the noun do not match with respect to syntactic gender. And, just as in the gender disagreement condition of Experiment 1 , gender disagreement leads to a general prolongation of lexical decision times, as compared with the other syntactic context conditions.

These results strongly suggest that the subjects restructure the scrambled prime sequences to form a correct declarative sentence. The main support for this assumption comes from the fact that the (nonscrambled) gender disagreement condition of Experiment 1 shows the same pattern of results as does the scrambled gender disagreement condition of Experiment 2.5

Finally, the absence of a priming effect in the question condition might indicate that the amount of priming in syntactically correct sequences is at least partially dependent on the distance between the verb and the target noun. However, it should be noted that making lexical decisions (yes/no reaction) to the last word of yes/no questions might also be responsible for this result.

Table 4

Lexical Decision Times (in Milliseconds) as a Function of Syntactic Context and Lexical Relatedness in Experiment 2 Syntactic Context

\begin{tabular}{|c|c|c|c|c|c|c|c|c|c|c|c|c|}
\hline \multirow[b]{2}{*}{ Relatedness } & \multicolumn{3}{|c|}{ Grammatical } & \multicolumn{3}{|c|}{ Scrambled } & \multicolumn{3}{|c|}{$\begin{array}{c}\text { Scrambled Gender } \\
\text { Disagreement }\end{array}$} & \multicolumn{3}{|c|}{ Question } \\
\hline & $\begin{array}{l}\text { Decision } \\
\text { Times }\end{array}$ & $S D$ & $\begin{array}{c}\% \\
\text { Incorrect }\end{array}$ & $\begin{array}{c}\text { Decision } \\
\text { Times }\end{array}$ & $S D$ & $\begin{array}{c}\% \\
\text { Incorrect }\end{array}$ & $\begin{array}{l}\text { Decision } \\
\text { Times }\end{array}$ & $S D$ & $\begin{array}{c}\% \\
\text { Incorrect }\end{array}$ & $\begin{array}{l}\text { Decision } \\
\text { Times }\end{array}$ & $S D$ & $\begin{array}{c}\% \\
\text { Incorrect }\end{array}$ \\
\hline Related & 588 & 110 & 0.0 & 598 & 114 & 1.6 & 635 & 126 & 1.2 & 596 & 115 & 2.8 \\
\hline Unrelated & 609 & 111 & 1.6 & $6[7$ & 121 & 0.6 & 642 & 128 & 2.8 & 605 & 112 & 4.7 \\
\hline$M$ & 599 & & & 608 & & & 638 & & & 600 & & \\
\hline
\end{tabular}


In both experiments reported above, the overall interaction between relatedness and syntactic context was not significant. We had proposed that this was due to insufficient power of the design. Since the subjects appeared to reconstruct the primes in the scrambled gender disagreement condition as grammatical sequences, we performed an analysis across the two experiments with the factors experiment (Experiment 1 vs. Experiment 2), syntactic context (grammatical vs. gender disagreement), and relatedness (related vs. unrelated). This analysis showed significant main effects of the factor experiment $\left[F_{1}(1,112)=3.2, M S_{\mathrm{e}}=18,473 ; F_{2}(1,32)=39.1, M S_{\mathrm{e}}=\right.$ 932], of the factor syntactic context $\left[F_{1}(1,112)=124.4\right.$, $\left.M S_{\mathrm{e}}=2,064 ; F_{2}(1,32)=20.8, M S_{\mathrm{e}}=7,721\right]$, and of the factor relatedness $\left[F_{1}(1,112)=14.9, M S_{\mathrm{e}}=1,794 ; F_{2}(1,32)=\right.$ 33.7, $\left.M S_{\mathrm{e}}=730\right]$. Most important, the interaction of syntactic context and relatedness was significant $\left[F_{1}(1,112)=\right.$ $\left.3.98, M S_{\mathrm{e}}=2,196 ; F_{2}(1,32)=4.5, M S_{\mathrm{e}}=1,004\right]$. All other interactions clearly failed to reach significance.

Until now, the present data lead to two main conclusions. First, in contrast to O'Seaghdha (1989) and Simpson et al. (1989), we obtain priming effects with grammatical as well as with scrambled prime sequences. This is presumably owing to the fact that our materials did allow for an implicit restructuring of the scrambled sequences to correct sequences, whereas the materials used by O'Seaghdha and Simpson et al. did not (see also note 5). With respect to our main issue-namely, the semantic relatedness effects in sequences with and without a violation of gender congruency between the article and the target noun-we observe a consistent reduction of the semantic relatedness effect in conditions with gender disagreement, as compared with conditions with gender agreement. The corresponding interaction, however, only reached significance in an analysis collapsing the results from Experiments 1 and 2.

Therefore, in Experiment 3, our aim was to provide more robust statistical evidence for the modulation of the semantic relatedness effect by gender disagreement. As the subjects appeared to be able to restructure scrambled prime sequences in Experiments 1 and 2, we tried to increase the statistical power for detecting the critical interaction by including only four conditions in Experiment 3 . These four conditions resulted from the crossing of the factors relatedness (related vs. unrelated) and syn- tactic context (gender congruency vs. incongruency between the article and the target noun).

\section{EXPERIMENT 3}

\section{Method}

Subjects. Forty native speakers of German, most of them students at the Free University of Berlin, participated in the experiment. They were either paid or received course credit for their participation.

Materials. The 40 triplets of two verbs and a target noun of Experiments 1 and 2 were used in the construction of the materials. From each triplet, four prime target sequences, one for each of the four experimental conditions, were constructed (for examples, see Table 1, conditions A, B, E, and F). Four experimental lists were constructed such that, within each list, 10 of the 40 target nouns occurred in one of the four conditions. Across the four experimental lists, each target noun occurred precisely once in each of the four conditions. For the nonword trials, the same verbnonword pairs as those in Experiments 1 and 2 were used. For the nonword targets, all prime sequences were syntactically correct.

Procedure. The procedure was the same as that in Experiments 1 and 2. Ten subjects were run on each experimental list.

\section{Results and Discussion}

Erroneous responses (1.95\% of all data points) were excluded from further analysis. Extreme reaction times $(1.8 \%)$ were determined and substituted by estimates, as in Experiments 1 and 2. Table 5 gives the mean lexical decision times and the percentages of incorrect responses in the four experimental conditions.

The ANOVAs showed no significant main effect of relatedness $\left[F_{1}(1,39)=2.63, M S_{\mathrm{e}}=1,811 ; F_{2}(1,36)=2.7\right.$, $\left.M S_{\mathrm{e}}=1,788\right]$. The main effect of syntactic context was significant $\left[F_{1}(1,39)=24.4, M S_{\mathrm{e}}=1,636 ; F_{2}(1,36)=\right.$ $\left.27.3, M S_{\mathrm{e}}=1,461\right]$, as was the interaction of relatedness and syntactic context $\left[F_{1}(1,39)=4.5, M S_{\mathrm{e}}=1,211\right.$; $\left.F_{2}(1,36)=4.8, M S_{\mathrm{e}}=1,089\right]$. A Newman-Keuls test $(p<$ .05 ) showed that all pairwise comparisons among the four means were significant, except for the relatedness effect (related vs. unrelated) in the gender disagreement condition.

Taken together, the results of Experiment 3 corroborate the corresponding results of Experiments 1 and 2. A gender mismatch between the prime fragment and the target noun leads to an overall prolongation of lexical decision times, as compared with conditions with gender match. In addition, a gender mismatch reduces or elimi-

Table 5

Lexical Decision Times (in Milliseconds) as a Function of Syntactic Context and Lexical Relatedness in Experiment 3

\begin{tabular}{|c|c|c|c|c|c|c|}
\hline \multirow[b]{3}{*}{ Relatedness } & \multicolumn{6}{|c|}{ Syntactic Context } \\
\hline & \multicolumn{3}{|c|}{ Grammatical } & \multicolumn{3}{|c|}{ Gender Disagreement } \\
\hline & $\begin{array}{c}\text { Decision } \\
\text { Times } \\
\end{array}$ & $S D$ & $\begin{array}{c}\% \\
\text { Incorrect }\end{array}$ & $\begin{array}{c}\text { Decision } \\
\text { Times }\end{array}$ & $S D$ & $\begin{array}{c}\% \\
\text { Incorrect }\end{array}$ \\
\hline Related & 573 & 90 & 1.8 & 617 & 100 & 2.0 \\
\hline Unrelated & 596 & 78 & 0.5 & 616 & 84 & 3.5 \\
\hline$M$ & 584 & & & 616 & & \\
\hline
\end{tabular}


nates a semantic priming effect between a prime verb and a target noun.

\section{GENERAL DISCUSSION}

As in previous, related research (e.g., Masson, 1986; O'Seaghdha, 1989; Simpson et al., 1989), the aim of the present study was to test lexical level and sentence level context effects by presenting lexically related primetarget pairs in different types of syntactic context. But before embarking on a general discussion of this issue, we would like to comment on the relationship between this type of research and the issue of autonomous lexical processing. The dependency of lexical priming effects on the syntactic correctness of the embedding sentences is often taken as an argument against models assuming autonomy of lexical processing. In our view, this is not necessarily a valid argument, as this type of research does not provide clear evidence as to the precise locus of the influence of syntactic context on lexical relatedness effects-in particular, as the lexical decision task is taken to tap postaccess processes in word recognition. For this reason, we will, in the following, largely refrain from interpreting the present results in the context of the discussion about autonomy of lexical processing.

The present data contrast with the results of O'Seaghdha (1989) and Simpson et al. (1989) insofar as lexical priming effects did obtain in scrambled word lists. However, the overall pattern of results strongly suggests that the subjects in the present experiments, unlike the subjects in O'Seaghdha's and Simpson et al.'s experiments, reconstructed the scrambled prime fragments (which consisted of only three words) into grammatical sentences. This could be due to the fact that, in the present experiments, the complete prime fragment was presented at once, whereas, in the studies by O'Seaghdha and Simpson et al., the prime fragment was presented word by word. Furthermore, the scrambling manipulation used in the present experiments is minor, as compared with those used by O'Seaghdha and by Simpson et al. (see note 5).

The main result of the present experiments concerns the influence of morphosyntactic information on the pattern of priming between associatively related words. In the gender disagreement conditions of Experiments 1,2, and 3 , priming effects were not significant. That is, a rather local morphosyntactic incorrectness reduced or eliminated the lexical relatedness effect. This extends the results obtained by O'Seaghdha (1989) and Simpson et al. (1989), who demonstrated the absence of priming effects in scrambled word lists. In the following, we will discuss this modulation of the lexical relatedness effect by gender disagreement in the context of previous studies that investigated the general influence of gender information on the recognition of a target noun.

In a study on German, Schmidt (1986) presented subjects with a definite article as prime and a noun as target. Lexical decision times to nouns in gender-incongruent article-noun pairs were longer than in a neutral baseline condition. However, evidence for facilitation in gendercongruent article-noun pairs was only obtained under special additional manipulations (e.g., masking the target noun). Similar results were obtained by Gurjanov et al. (1985) for Serbo-Croatian. In this study, SerboCroatian possessive pronouns that are inflectionally marked for gender served as primes, and nouns served as targets. Gender-congruent prime-target pairs led to faster lexical decisions than did gender-incongruent ones. Gurjanov et al. interpreted this result as being the outcome of a response competition between the positive response initiated by the lexical processor and a negative response initiated by the syntactic process in the case of genderincongruent pairs. For French, Colé and Segui (1994) also reported longer lexical decision times for target nouns preceded by gender-incongruent primes than for target nouns preceded by gender-congruent primes. Taken together, these results suggest that the effect of syntactic gender information in context-target combinations is primarily of an inhibitory nature. This account implies that syntactic gender information preceding a noun does not preactivate the whole set of gender-matching nouns in the mental lexicon. On the other hand, Grosjean et al. (1994) have recently reported facilitation effects by gender-congruent primes, relative to a gender-neutral baseline in French. Comparable results have been obtained by Bates et al. (1996) for Italian. However, whether these facilitation effects are really due to a preactivation of the complete set of nouns having the same grammatical gender as the prime is as yet not clear. As Tanenhaus et al. (1987) argue, such a preactivation of large zones of the mental lexicon (e.g., a masculine definite determiner activating all nouns of masculine gender) should, presumably, be ineffective. The set of preactivated lexical elements would be so large that preactivation of this whole set would not lead to efficient discrimination between candidate words and noncandidate words. Similarly, Bates et al. (1996) argue that gender priming should not be seen as a simple intralexical spreading of activation from gender information to all lexical elements of the corresponding gender. They argue that such a mechanism might do more harm than good in sentence processing. They illustrate this by the following example from Italian:

Perche la trova cosi bella, Giovanni ha invitato Maria

Because her (fem., obj., clitic) finds so beautiful (fem.), John (masc.) invited Maria (fem.)

Here, the feminine adjective bella (beautiful) modifies Maria, but it immediately precedes the masculine noun Giovanni (John). Bates et al. (1996) argue that a "blind" structure-independent spreading activation from gender information might lead to a situation in which the gender information on bella will erroneously block or inhibit perception of the next noun (i.e., Giovanni).

A plausible alternative to preactivation considers gender information to be useful information for a (structuredependent) reduction of lexical candidates that have 
been activated by the semantic context (Bates et al., 1996). We will return to this alternative below.

As far as the general inhibitory effect of gender incongruency is concerned, the present results are in agreement with those obtained by Gurjanov et al. (1985), Schmidt (1986), and Colé and Segui (1994). However, the crossing of gender in-/congruency between the article and the noun with the associative relation between the prime verb and the target noun in the present study shows that gender disagreement can have an effect above and beyond a general inhibitory effect. This additional effect concerns the reduction or elimination of lexical-lexical priming of a target noun in the case of gender disagreement between the definite article and the target noun.

How does this finding relate to the different models of context effects on lexical processing? Discourse-oriented models assume that context effects have their source in higher level structures outside the lexicon. Context effects are a reflection of the ease with which a target word can be integrated in the ongoing discourse or sentence representation, the result of top-down influences from the discourse or sentence representation that directly activate particular lexical elements in the mental lexicon, or the results of some combination of these two factors. As Hess et al. (1995) point out, the available evidence on sentence and discourse context effects makes it difficult to decide between these alternatives. As an attempt at bringing together the priming results from word list, sentence, and discourse studies, they propose that "subjects may be particularly sensitive to coherence relations at the highest level the materials permit" (p. 81). For example, whereas, in word lists, subjects will be responsive to relations among individual words, in sentence processing, coherence relations at the sentence level are primary. Under this view, the present data provide a constraint on what the relevant level of coherence in sentence processing is. In the case of a gender mismatch between article and noun, the subjects are not able to neglect this local syntactic incoherence (within a noun phrase) and to rely on the semantic coherence of the sentence (i.e., the semantic coherence between the verb and the noun phrase). Rather, a local morphosyntactic incoherence appears to block the semantic integration of the target noun in the sentence context.

We had already mentioned above the more localist account of gender priming effects that has been proposed by Bates et al. (1996). For the present results, this account could take the following form. The prime verb in the related condition activates a set of associatively related nouns. The gender information carried by the definite article reduces this set of nouns to only those of matching syntactic gender. In the present case, the verb in the sentence prime may activate a set of candidate nouns via lexical-lexical priming. This set of candidate nouns can then be reduced on the basis of other contextual information, such as, in the present experiments, the gender information carried by the definite article. It should be noted that such an account avoids the problematic assumption that gender information on an article can preactivate large zones of the mental lexicon-namely, all nouns of matching gender (see Bates et al., 1996; Tanenhaus et al., 1987).

Taken together, the present results show that a gender mismatch between a prime and a target has an influence on word recognition beyond a general inhibitory effect that is, presumably, based on the negative outcome of a syntactic procedure that checks whether the gender agreement rule is being respected or not. Rather, the gender mismatch reduces or eliminates lexical-lexical priming effects. This result could be accounted for by a discourse- oriented model of context effects on lexical processing, as well as by a localist lexical account. However, for both views, the present data provide constraints on how lexical - lexical relatedness effects can be modulated by syntactic context.

\section{REFERENCES}

Auble, P., \& Franks, J. J. (1983). Sentence comprehension processes Journal of Verbal Learning \& Verbal Behavior, 22, 395-405.

Bates, E., Devescovi, A., Hernandez, A., \& Pizzamiglio, L. (1996). Gender priming in Italian. Perception \& Psychophysics, 58, 9921004 .

Bates, E., Devescovi, A., Pizzamiglio, L., D’Amico, S., \& HernanDEZ, A. (1995). Gender and lexical access in Italian. Perception \& Psychophysics, 57, 847-862.

CoLé, P., \& SEGUI, J. (1994). Grammatical incongruency and vocabulary types. Memory \& Cognition, 22, 387-394.

Deutsch, A., \& Bentin, S. (1994). Attention mechanisms mediate the syntactic priming effect in auditory word identification. Journal of Experimental Psychology: Learning, Memory, \& Cognition, 20, 595-607.

Fischler, I., \& BloOM, P. A. (1979). Automatic and attentional processes in the effects of sentence context on word recognition. Journal of Verbal Learning \& Verbal Behavior, 18, 1-20.

Foss, D. J., \& Ross, J. R. (1983). Great expectations: Context effects during sentence processing. In G. Flores d'Arcais \& R. J. Jarvella (Eds.), The process of language understanding (pp. 169-191). Chichester, U.K.: Wiley.

Foss, D. J., \& SPEER, S. R. (1991). Global and local context effects in sentence processing. In R. R. Hoffman \& D. S. Palermo (Eds.), Cognition and the symbolic processes: Applied and ecological perspectives (pp. 115-139). Hillsdale, NJ: Erlbaum.

Friederici, A. D., \& Schriefers, H. (1994). The nature of semantic and morphosyntactic context effects on word recognition in young healthy and aphasic adults. Linguistische Berichte, 6, 9-32.

Grosjean, F., Dommergues, J.-Y., Cornu, E., Guillelmon, D., \& Besson, C. (1994). The gender-marking effect in spoken word recognition. Perception \& Psychophysics, 56, 590-598.

Gurjanov, M., Lukatel.a, G., Moskoljevic, J., Savic, M., \& Turvey, M. T. (1985). Grammatical priming of inflected nouns by inflected adjectives. Cognition, 19, 55-71.

Hess, D. J., Foss, D. J., \& Carrol., P. (1995). Effects of global and local context on lexical processing during language comprehension. Journal of Experimental Psychology: General, 124, 62-82.

Katz, L., Boyce, S., Goldstein, L., \& Luxatela, G. (1987). Grammatical information effects in auditory word recognition. Cognition, $25,235-263$

Lorch, R. F., Balota, D. A., \& Stamm, E. G. (1986). Locus of inhibition effects in the priming of lexical decisions: Pre- or postlexical access? Memory \& Cognition, 14, 95-103. 
Lukatela, G., Carello, C., \& Turvey, M. T. (1990). Phonemic, associative, and grammatical context effects with identified and unidentified primes. Language \& Speech, 33, 1-18.

lukatel A, G., Kostic, A., Todorovic, D., Carello, C., \& Turvey, M. T. (1987). Type and number of grammatical violations and the grammatical congruency effect in lexical decision. Psychological Research, 49, 37-43.

Masson, M. E. J. (1986). Comprehension of rapidly presented sentences: The mind is quicker than the eye. Journal of Memory \& Language, 25, 588-604.

NeELy, J. H. (1990). Semantic priming effects in visual word recognition: A selective review of current findings and theories. In D. Besner \& G. W. Humphreys (Eds.), Basic processes in reading: Visual word recognition (pp. 236-264). Hillsdale, NJ: Erlbaum.

O'Seaghdha, P. G. (1989). The dependence of lexical relatedness effects on syntactic connectedness. Journal of Experimental Psychology: Learning, Memory, \& Cognition, 15, 73-87.

RuECKLE, J. G., \& ODEN, G. C. (1986). The integration of contextual and featural information during word identification. Journal of Memory \& Language, 25, 445-460.

Sanocki, T., Goldman, K., Waltz, J., Cook, C., Epstein, W., \& ODEN, G. C. (1985). Interaction of stimulus and contextual information during reading: Identifying words within sentences. Memory \& Cognition, 13, 145-157.

SchmidT, R. (1986). Was weiß der Artikel vom Hauptwort? Ein Beitrag zur Verarbeitung syntaktischer Beziehungen beim Lesen. Zeitschrift für experimentelle \& angewandte Psychologie, 33, 150163.

SChustack, M. W., Ehrlich, S. F., \& Rayner, K. (1987). Local and global sources of contextual facilitation in reading. Journal of Memory \& Language, 26, 322-340.

Seidenberg, M. S., Tanenhaus, M. K., Leiman, J. M., \& BienkowSKI, M. (1982). Automatic access of the meanings of ambiguous words in context: Some limitations of knowledge based processing. Cognitive Psychology, 14, 489-537.

SeidenberG, M. S., Waters, G. S., Sanders, M., \& Langer, P. (1984). Pre- and postlexical loci of contextual effects on word recognition. Memory \& Cognition, 12, 315-328.

Simpson, G. B., Peterson, R. R., Casteel, M. A., \& Burgess, C. (1989). Lexical and sentence context effects in word recognition. Journal of Experimental Psychology: Learning, Memory, \& Cognition, 15, 88-97.

STANOVICH, K. E., \& WeSt, R. F. (1979). Mechanisms of sentence context effects in reading: Automatic activation and conscious attention. Memory \& Cognition, 7, 77-85.

Stanovich, K. E., \& WEST, R. F. (1983). On priming by a sentence context. Journal of Experimental Psychology: General, 112, 1-36

Tanenhaus, M. K., Dell, G. S., \& Carlson, G. (1987). Context effects and lexical processing: A connectionist approach to modularity. In J. L. Garfield (Ed.), Modularity in knowledge representation and natural-language processing (pp. 83-108). Cambridge, MA MIT Press.
WAHLSTEN, D. (1991). Sample size to detect a planned contrast and a one degree-of-freedom interaction effect. Psychological Bulletin, $110,587-595$.

West, R. F., \& Stanovich, K. E. (1982). Source of inhibition in experiments on the effect of sentence context on word recognition. Journal of Experimental Psychology: Learning, Memory, \& Cognition, 5, 385-399.

WEST, R. F., \& Stanovich, K. E. (1986). Robust effects of syntactic structure on visual word processing. Memory \& Cognition, 14, 104112.

WILCOx, R. R. (1987). New designs in analysis of variance. Annual Review of Psychology, 38, 29-60.

WINER, B. J. (1971). Statistical principles in experimental design. New York: McGraw-Hill.

WRIGHT, B., \& GARRETT, M. (1984). Lexical decision in sentences: Effects of syntactic structure. Memory \& Cognition, 12, 31-45.

ZWITSERLOOD, P. (1989). The locus of the effects of sententialsemantic context in spoken word processing. Cognition, 32, 25-64.

\section{NOTES}

1. We have to add here that one can only compare the size of the priming effects, but not the absolute reaction times in $\mathrm{A}$ and $\mathrm{B}$, on the one hand, and $\mathrm{G}$ and $\mathrm{H}$, on the other hand, because the target nouns in the latter two conditions differ from the target nouns in the former two conditions (nouns in plural vs. singular form).

2. The use of nouns of masculine and neuter syntactic gender was motivated by the conditions to be used in Experiments 1-3. The accusative feminine definite article for feminine die is ambiguous between singular and plural and was, therefore, not used.

3. As the overall latencies between the two groups of subjects run on the two experimental lists differed by only $8 \mathrm{msec}$, group differences presumably did not influence the priming effects for individual items.

4. As there were 23 neuter and 17 masculine nouns, seven sets of five items consisted of 3 neuter and 2 masculine nouns, and one set consisted of 2 neuter and 3 masculine nouns.

5. The fact that the subjects of the present experiment were in principle able to restructure scrambled prime sequences, whereas this appears not to hold for O'Seaghdha's (1989) and Simpson et al.'s (1989) experiments, presumably is due to a difference in the scrambling method. Whereas, in the present experiments, we reordered the words of grammatical sequences, $O$ 'Seaghdha exchanged function words between scrambled experimental sentences in addition. This additional manipulation might have made it impossible to restructure scrambled sequences to form correct sequences. In Simpson et al.'s study, the sentences were longer and of varying syntactic structures. Therefore, in this study too, restructuring scrambled sequences was less likely to occur than it was for the sequences used in the present study.

(Manuscript received June 11, 1996; revision accepted for publication May 4, 1997.) 